\title{
Practical application of Eurocode provisions to design a steel frame of a building classified to the upper risk group
}

\author{
Wioleta Barcewicz ${ }^{1, *}$ and Forat Al-Sahar ${ }^{1}$ \\ ${ }^{1}$ Warsaw University of Technology, Faculty of Civil Engineering, Division of Metal Structures, Warsaw, Poland
}

\begin{abstract}
Within the framework of this paper, the design of steel structure of the eight-storey building intended for a hotel is carried out, on the basis of Eurocodes. According to EN 1991-1-7, the building is classified to the upper risk group - $\mathrm{CC} 2 \mathrm{~b}$ and therefore additional requirements to the design has to be applied. The steel structure of the building should be checked in order to sustain an extent of localised failure from an unspecified cause without disproportionate collapse. It has been achieved by the three-part studies. In the first part, the frame structural members and the semi-rigid beam-to-column joints are verified for the normal design situation. The second part is related to the study of the structure subject to accidental damage due to a column loss. Three various accidental load cases are considered, in which the columns of the lowest storey are removed from three different positions. Finally, a design of the frame subject to the accidental situation has been performed using the key elements method based on the selection of the structural elements that are notified as the most critical and adoption of the recommended value of the accidental load, simulating an exceptional event within the accidental load combinations.
\end{abstract}

\section{Introduction}

The basic requirements for designing building structures set out in EN 1990 [1] are to provide their adequate structural resistance, serviceability and durability. The relevant design situations should be properly selected taking into account the circumstances under which the structure is required to fulfil its function, including not only normal (persistent and transient) load cases but also exceptional conditions. A structure should be designed that it will not be damaged by extreme events such as an explosion, impact, and the consequences of human errors, to an extent disproportionate to the original cause. The exceptional situations that need to be considered are set out in EN 1991-1-7 [2] and relate to both identified accidental actions and unidentified accidental actions.

A strategy to be adopted in either case depends on three classes introduced in [1], based on the assumed consequences of failure and the exposure of the construction works to hazard. The least restrictive class $\mathrm{CC} 1$ refers to low consequence for loss of human life, and small or negligible economic, social or environmental consequences (e.g. agricultural buildings or low single occupancy houses). In contrary to the most restrictive class CC3 with high consequence for loss of human life, and very great economic, social or environmental consequences (e.g. grandstands or public buildings where consequences of failure are high). The more detailed categorisation of building type is given in [2], where, besides, Class CC2 has been subdivided into two groups, CC2a (lower risk) and $\mathrm{CC} 2 \mathrm{~b}$ (upper risk). Examples describing the specific building types within the subdivided CC2 consequences class are shown in Table 1 .

Table 1. Examples of buildings categorisation for CC2 [2].

\begin{tabular}{|c|c|}
\hline $\begin{array}{l}\text { Consequence } \\
\text { class }\end{array}$ & $\begin{array}{c}\text { Example of categorization } \\
\text { of building type and occupancy }\end{array}$ \\
\hline $\begin{array}{l}\text { CC2a } \\
\text { Lower Risk } \\
\text { Group }\end{array}$ & $\begin{array}{l}\text { Five-storey single occupancy houses; } \\
\text { Residential buildings, hotels and offices not } \\
\text { exceeding } 4 \text { storeys; } \\
\text { Industrial buildings not exceeding } 3 \text { storeys } \\
\text { Retailing premises not exceeding } 3 \text { storeys } \\
\text { (<1000 } \mathrm{m}^{2} \text { floor area in each storey); } \\
\text { Single storey educational buildings; } \\
\text { All buildings not exceeding } 2 \text { storeys to } \\
\text { which the public are admitted and which } \\
\text { contain floor areas not exceeding } 2000 \mathrm{~m}^{2} \\
\text { at each storey. }\end{array}$ \\
\hline $\begin{array}{c}\text { CC2b } \\
\text { Upper Risk } \\
\text { Group }\end{array}$ & $\begin{array}{l}\text { Residential buildings, hotels and offices } \\
\text { greater than } 4 \text { but not exceeding } 15 \text { storeys; } \\
\text { Educational buildings greater than } 1 \text { but not } \\
\text { exceeding } 15 \text { storeys; } \\
\text { Hospitals not exceeding } 3 \text { storeys } \\
\text { Retailing premises greater than } 3 \text { storeys } \\
\text { but not exceeding } 15 \text { storeys; } \\
\text { All buildings to which the public are } \\
\text { admitted and which contain floor areas } \\
\text { exceeding } 2000 \mathrm{~m}^{2} \text { at each storey; } \\
\text { Car parking not exceeding } 6 \text { storeys. }\end{array}$ \\
\hline
\end{tabular}

Strategies based on unidentified accidental actions cover a wide range of possible events and are related to strategies based on limiting the extent of localised failure [3]. Structures should be designed to have an appropriate

* Corresponding author: wb@il.pw.edu.pl 
level of robustness. Robustness is defined in [4] as the ability of a structure or structural components to resist damage without premature and/or brittle fracture due to events like explosions, impacts, fires or consequences of human error, due to its vigorous strength and toughness. In [2], robustness is described as the ability of a structure to withstand accidental events without being damaged to an extent disproportionate to the original cause.

The potential failure of the structure arising from an unspecified cause should be mitigated by adopting one or more of the following approaches [2]:

- designing key elements on which the stability of the structure depends, to sustain the effects of a model of accidental action $\mathrm{A}_{\mathrm{d}}$;

- designing the structure so that in the event of a localized failure (e.g. failure of a single member) the stability of the whole structure or a significant part of it would not be endangered;

- applying prescriptive design detailing rules that provide acceptable robustness for the structure (e.g. threedimensional tying for an additional integrity, or a minimum level of ductility of structural members subject to impact [5]).

Depending on a selected consequences class of a structural arrangement, in EN 1991-1-7 [2] one can find recommended problems to be solved. For structures classified to $\mathrm{CC} 1$, no specific consideration is necessary for accidental actions from unidentified causes except to ensure that the stability rules given in Eurocodes for normal use are met. While for the highest class CC3, an examination of the specific case should be carried out to determine the level of reliability and complexity of structural analyses required. This may require a risk analysis to be carried out and the use of refined methods such as dynamic analyses, non-linear models and interaction between the load and the structure [6-8]. For class $\mathrm{CC} 2 \mathrm{a}$ structures, in addition to the recommended strategies for class $\mathrm{CC} 1$, the provision of effective horizontal ties, or effective anchorage of suspended floors to walls should be provided. Building structures of consequences class $\mathrm{CC} 2 \mathrm{~b}$ (in addition to the recommended strategies for class $\mathrm{CC} 1$ ) have to be considered in one of two alternative ways [2]:

- horizontal ties together with vertical ties in all supporting columns and walls should be provided or alternatively;

- the building should be checked to ensure that upon the notional removal of each supporting column and each beam supporting a column, or any nominal section of load-bearing wall (one at a time in each storey of the building), the building remains stable and that any local damage does not exceed a certain limit. Where the notional removal of such columns and sections of walls would result in an extent of damage in excess of the agreed limit, or other such limit specified, then such elements should be designed as a "key element".

The aim of this paper is to apply the latter from the requirements and provisions mentioned above to a practical worked example. It allows presenting the differences in designing a steel frame of the assumed multi-storey building, classified to the upper risk group (CC2b) for a normal design situation and for an accidental design situation. Static analysis and design results for these two representative cases have been compared in order to assess the increase of steel use when the robustness design approach is taken into consideration.

\section{Description of the frame model}

As the reference model for the undertaken case study, the eight-storey hotel is taken into consideration, following the assumptions covered in the Master thesis [9] of the second author, under the supervision of the first author of this paper. According to Table 1, the selected building type may be classified as class $\mathrm{CC} 2 \mathrm{~b}$, i.e. the upper risk group of the middle consequences class.

\subsection{Geometry and static scheme of the frame}

The building, of dimensions $27.0 \mathrm{~m}$ (width) $\times 36.0 \mathrm{~m}$ (length), consists of seven steel frames. Each frame is consisted of five bays (two external bays of $6.0 \mathrm{~m}$ on both sides of the frame and the middle bay of $3.0 \mathrm{~m}$ ), as shown in Fig. 1.

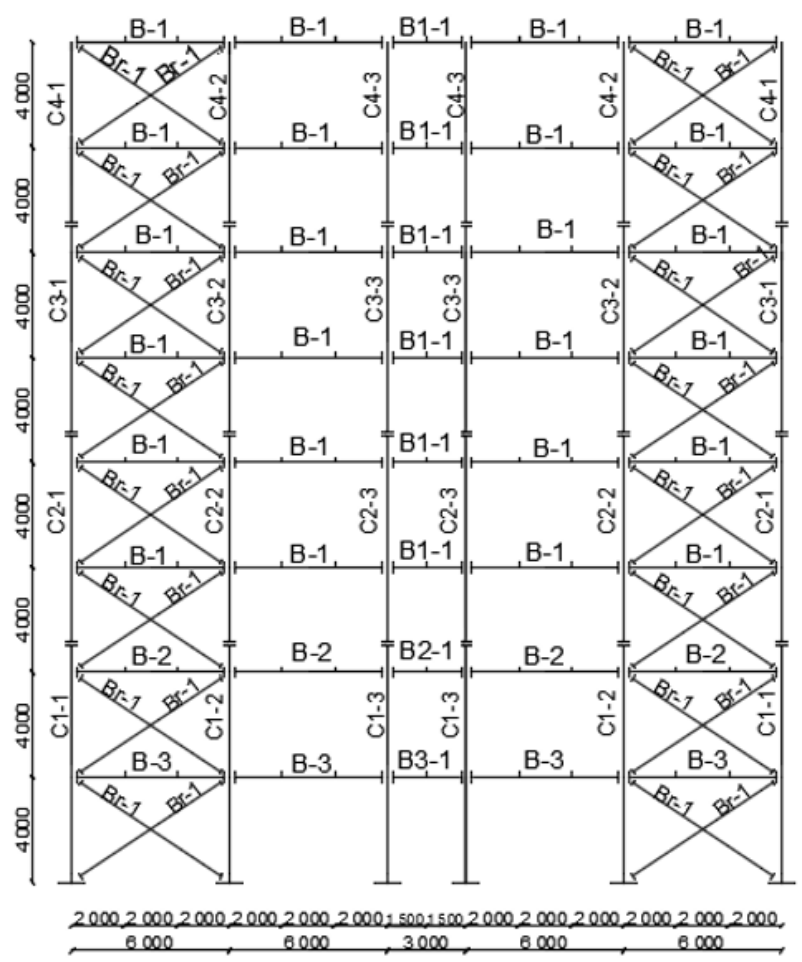

Fig. 1. View of the analysed steel frame.

The frames are spaced $6.0 \mathrm{~m}$ from each other. The height of each individual storey is $4.0 \mathrm{~m}$. Therefore, the total height of the building is $32.0 \mathrm{~m}$. In order to ensure the global stability of the structure, the corner bays and segments are braced vertically in longitudinal and transversal directions. The adjacent frames are connected by secondary beams, providing discrete lateral restrains to the frame members. While the analysed structure has been modelled as a $2 \mathrm{D}$ frame, the presence of the 
secondary beams is replaced by the supports which block the lateral displacement out-of-plane of the frame.

The columns are continuous and the column bases are assumed to be fixed in the frame plane and to be pinned in the out-of-plane direction. Bracing connections are considered as pinned joints. The primary beam-tocolumn joints are modelled as semi-rigid, in the form of bolted end-plate connections. Several types of joints are generated, taking into account configuration of a joint (single or double-sided), its location (top or intermediate floor), and the vicinity of structural members (longer or shorted beams, columns of different cross-sections). Rotational stiffness of different joint models is taken into consideration in the static analysis of the frame model.

\subsection{General assumptions for the design}

It is assumed that the designed hotel is located in the north-west part of Poland near lake surroundings. According to [10] and $[11,12]$, this location is classified as snow zone 2 (with the characteristic value of snow load on the ground of $0.9 \mathrm{kN} / \mathrm{m}^{2}$ ) and wind zone 1 (with the fundamental value of the basic wind velocity equal to $22 \mathrm{~m} / \mathrm{s}$ ), respectively.

Self-weight of the structural members of the frame is taken into account automatically by software for static calculations. Beams are made of hot-rolled IPE sections and columns of HEB, of S235 steel grade. The additional components of dead load include self-weight of steel secondary beams, roofing, insulation, and floor layers, as well as reinforced concrete slabs, ring beams, and external walls, suspended ceilings and building installations. The imposed load is set out according to [13], for recommended categories of use dedicated to hotel floor areas. The detailed list of all persistent and transient loads is presented in [9].

\subsection{Assessment methodology}

Structural analysis as well as joint design, a global check of the frame and separate verifications of the selected steel structural members are performed in computer program ConSteel 9.0, based on Finite Element Method. Computer calculations are based on the second-order analysis, preceded by an evaluation of buckling sensitivity and implementation of the global imperfections by means of the equivalent initial sway imperfection.

In the beginning, the building structure is designed considering the normal situation to which the steel frame with semi-rigid joints has been checked in terms of Ultimate Limit States and Serviceability Limit States, according to EN 1993-1-1 [14] and EN 1993-1-8 [15]. Then, three various accidental load cases are considered, in which different columns of the lowest storey are removed (one column at a time) and behaviour of the remained structure has been studied. Then, a design of the frame subjected to the accidental situation according to EN 1991-1-7 [2] has been performed using the key elements method. It is based on the selection of the structural elements that are notified as the most critical and on adoption of the recommended value of the accidental load, simulating an exceptional event. The design calculations of the most loaded members representing each section group are performed, taking into account the effects of flexural buckling, lateraltorsional buckling and their interactions. Finally, a comparison of the results obtained from the first and the second design case is discussed.

\section{Analysis of the frame subjected to the normal design situation}

A normal design situation in the Ultimate Limit States (ULS) is generated by the set of load combinations defined in [1] by the following expressions:

$$
\begin{gathered}
\Sigma\left(\gamma_{G, j} G_{k, j}\right)+\gamma_{Q, 1} \psi_{0,1} Q_{k, 1}+\Sigma\left(\gamma_{Q, i} \psi_{0, i} Q_{k, i}\right) \\
\Sigma\left(\xi_{j} \gamma_{G, j} G_{k, j}\right)+\gamma_{Q, 1} Q_{k, 1}+\Sigma\left(\gamma_{Q, i} \psi_{0, i} Q_{k, i}\right)
\end{gathered}
$$

where:

$\Sigma$ implies "the combined effect of", $G_{k, j}$ is the characteristic value of a permanent action, $Q_{k, 1}$ or $Q_{k, i}$ is the characteristic value of the leading variable action 1 or of the accompanying variable action $\mathrm{i}$, respectively,

$\gamma_{G, j}$ is the partial factor for permanent action $\mathrm{j}$, equal to 1.35 for unfavourable and 1.0 for favourable action,

$\gamma_{Q, 1}$ or $\gamma_{Q, i}$ is the partial factor for the leading variable action 1 or for an accompanying variable action $\mathrm{i}$, respectively, equal to 1.5 for unfavourable and 0 for favourable action,

$\psi_{0,1}$ or $\psi_{0, i}$ is the factor for combination value of the leading variable action 1 or for an accompanying variable action i, respectively, equal to 0.7 for imposed load, 0.5 for snow load and 0.6 for wind action, $\xi$ is a reduction factor for unfavourable permanent actions $\mathrm{G}$, equal to 0.85 .

\subsection{Load cases}

The load cases defined in ConSteel software, considered as the components of the normal design situation, consist of:

- G - dead load (including self-weight of the steel structure of the frame);

- five cases of the imposed load with different arrangements (Q1 - all intermediate floors, Q2 - alternate bays of the intermediate floors, Q3 opposite to Q2, Q4 two adjacent bays with the external bay included, and Q5 two adjacent bays with the middle bay included);

- three snow load cases (SL1 - undrifted, SL2 - drifted, SL3 opposite to SL2),

- five wind load cases (WL1 and WL3 - wind perpendicular to the longitudinal wall, for frames $3,4,5$ and frames 2, 6, respectively, WL2, WL4 and WL5 wind perpendicular to the gable wall, for zone $\mathrm{C}$, zone $\mathrm{A}$ and zone $\mathrm{B}$, respectively). 


\subsection{Sections of the frame structural members and beam-to-column joints}

The sections of the structural members are presented in Fig. 2. For all primary beams, IPE 400 is adopted, while for the columns different sections are optimised for every two storeys. Starting from the lowest storey upwards, there are following sections HEB 360, HEB 340, HEB 320, and HEB 240. In addition, the bracings in the frame have been modelled as L 160x80x12 mm. The chosen sections are sufficient enough to ensure the reduction of horizontal deflections by at least $80 \%$ in relation to the un-braced frame.

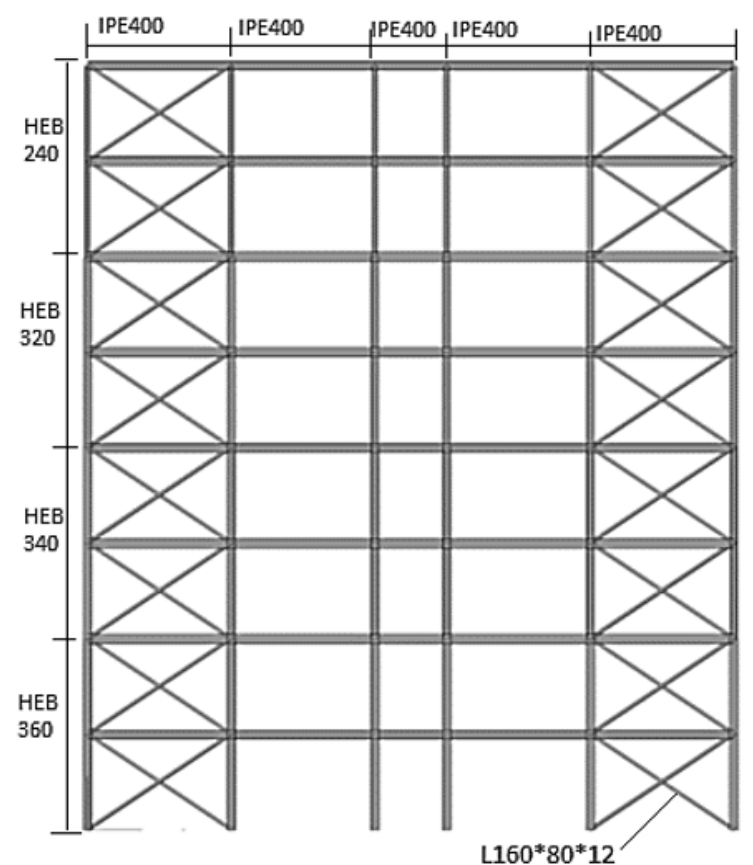

Fig. 2. Sections of the frame structural members in the normal design situation.

As mentioned before, the set of the semi-rigid beamto-column joints are generated in ConSteel software and placed in the frame model. Their structural properties are included in the static analysis of the frame. Details on joints are given in [9].

\subsection{Results of the static analysis}

The buckling analysis of the structure has been performed by interpreting the eigenvalue analysis which approximates the elastic critical load levels and some modes of loss in stability. Graphical interpretation of the eigenmode for the lowest value of the critical force multiplier $\alpha_{c r}$ is presented in Fig. 3.

The value of $\alpha_{c r}=6.24<10$ is obtained for the load combination, based on formula (2) and the load schemes described in subsection 3.2:

$$
1.15 \mathrm{G}+1.5 \mathrm{Q} 4+1.05 \mathrm{SL} 1+0.9 \mathrm{WL} 1
$$

and confirms the necessity of conducting the global analysis of the second order.

In the case of the design of the primary beams, the maximum bending moment is found in the span (sagging moment) of the primary beam located on the $7^{\text {th }}$ floor (Fig. 4) and equals $165.92 \mathrm{kNm}$. It is generated by the load combination given by the formula (4):

$$
1.15 \mathrm{G}+1.5 \mathrm{Q} 1+1.05 \mathrm{SL} 3+0.9 \mathrm{WL} 3
$$

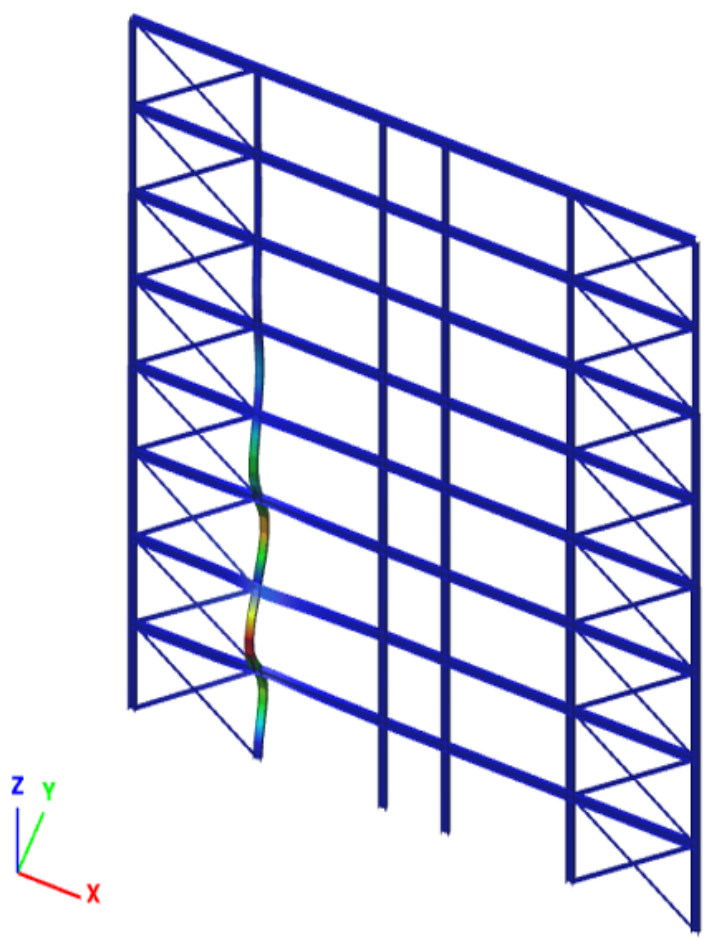

Fig. 3. View of the first eigenshape with the lowest $\alpha_{c r}$.

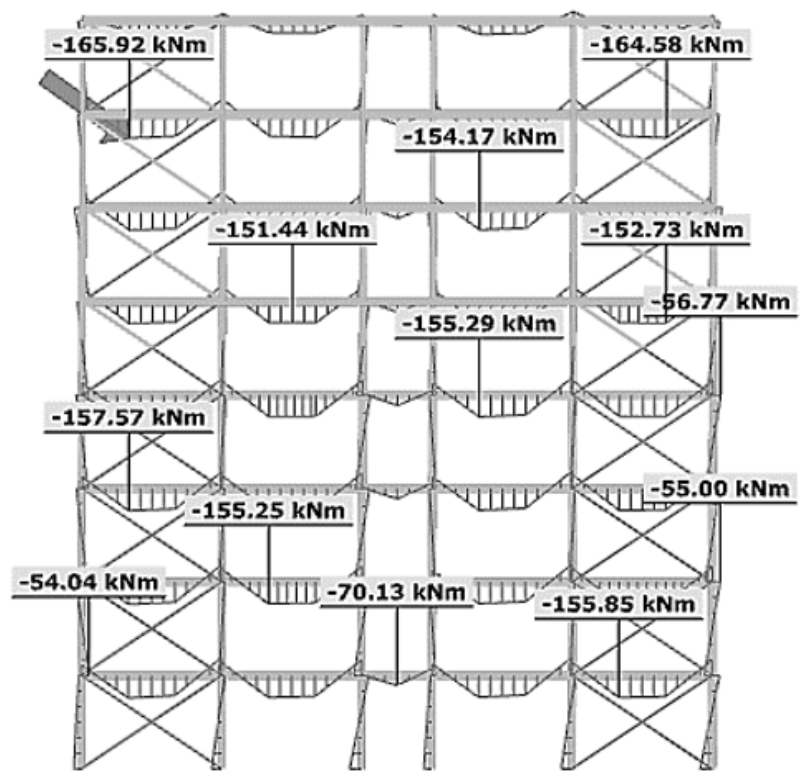

Fig. 4. Bending moment diagram with the max. $\mathrm{M}_{\mathrm{Ed}}$ indicated

For designing of the columns, the maximum normal force is selected on the basis of the load combination given by the formula (5):

$$
1.15 \mathrm{G}+1.5 \mathrm{Q} 4+1.05 \mathrm{SL} 2+0.9 \mathrm{WL} 1
$$

and is equal to $-3014.15 \mathrm{kN}$. The diagram of normal forces for the selected design load combination is shown in Fig. 5. 
Deformations in both vertical and horizontal directions have been verified for the Serviceability Limit States, obtaining satisfactory results [9].

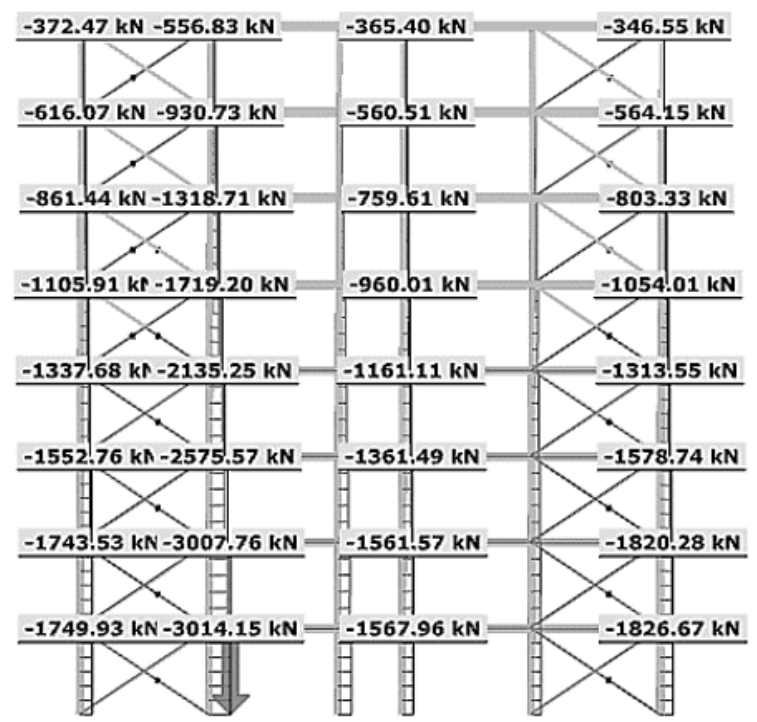

Fig. 5. Normal force diagram with the max. $\mathrm{N}_{\mathrm{Ed}}$ indicated.

\subsection{Design of the frame subject to the normal design situation}

Global check results of the analysed frame are given in Fig. 6. The most utilised structural members from each section group are also checked individually according to requirements of EN 1993-1-1 [14].

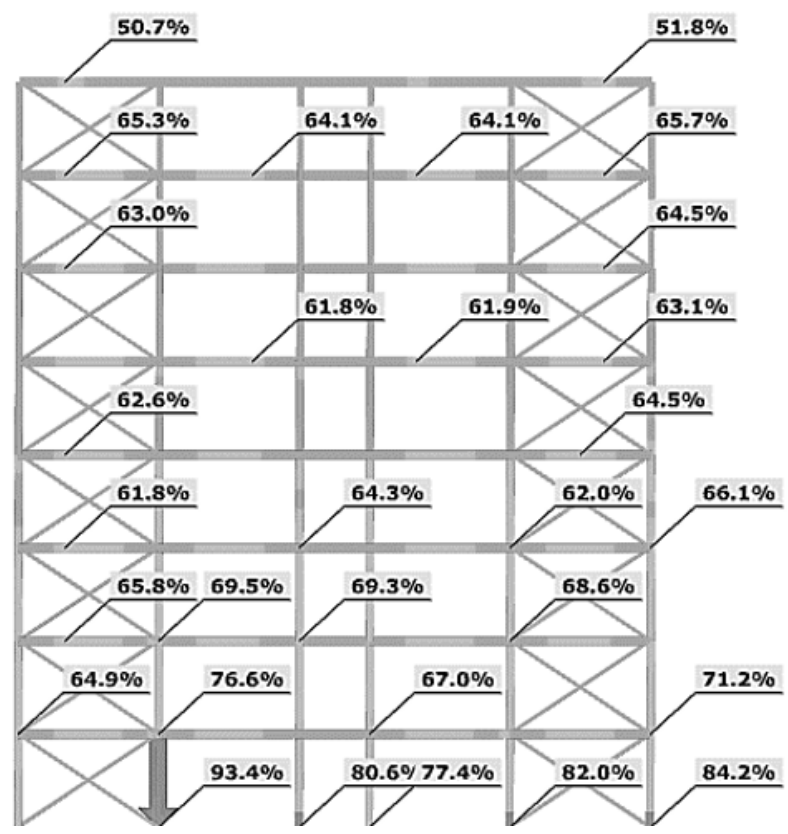

Fig. 6. The utilisation of the frame structural members.

\section{Analysis of the frame subjected to the accidental design situation}

Within this section, the analysed frame is tested to withstand accidental design situation. Such situation is generated by the load combination defined in [1] by the following formula:

$$
\Sigma G_{k, j}+A_{d}+\left(\psi_{1,1} \text { or } \psi_{2,1}\right) Q_{k, 1}+\Sigma\left(\psi_{2, i} Q_{k, i}\right)
$$

where:

$A_{d}$ is the design value of an accidental action, recommended by [2] to be taken as $34 \mathrm{kN} / \mathrm{m}^{2}$,

$\psi_{1,1}$ is the factor for frequent value of the leading variable action 1 , equal to 0.5 (residential areas of Category A) or 0.7 (congregation areas of Category C) for imposed load, 0.2 for snow load and 0.2 for wind action,

$\psi_{2,1}$ or $\psi_{2, i}$ is the factor for quasi-permanent value of the leading variable action 1 or for an accompanying variable action $i$, respectively, equal to 0.3 (Category $\mathrm{A}$ ) or 0.6 (Category C) for imposed load, 0 for snow load and 0 for wind action,

According to [2], before using formula (6), the proper strategy should be adopted for the buildings classified to CC2b upper risk group. Mainly, the building should be checked to ensure that upon the notional removal of each supporting column (one at a time in each storey of the building) the building remains stable and that any local damage does not exceed a certain limit. The limit of admissible local failure may be different for each type of building. However, the general recommendation is given in [2]. The recommended value is $15 \%$ of the floor area, or $100 \mathrm{~m}^{2}$, whichever is smaller, in each of two adjacent storeys.

Where the notional removal of the selected columns would result in an extent of damage in excess of the agreed limit, then such elements should be designed as a "key element".

\subsection{Accidental load cases}

For the purpose of the present research, the assessment of the frame behaviour is limited to three various accidental load cases, in which differently located columns of the lowest storey are removed (see Fig. 7):

- Case 1 - the middle column near the shortest span;

- Case 2 - the internal column near the braced bay;

- Case 3 - the external column near the braced bay.

On this basis, the behaviour of the remained structure has been studied in order to compare the number of the over-utilized frame members (primary beams and columns) and joints. The detailed results of non-linear second order global analysis and resistance verifications of the members and joints are presented in [9].

From this comparative analysis the following remarks are obtained:

- the biggest number of the over-utilized members is noticed in Case 2 (four primary beams and one column); for the comparison in Case 1 - only two primary beams and in Case 3 - three primary beams and one column are over-utilized;

- the highest utilization of the primary beam-tocolumn joint is observed in Case 2 due to the moment and axial force interaction; it is the internal joint directly above the column removal (similarly like in Case 1); in 
Case 3 (in which the external column was removed) the critical joint was in the same position as in Case 2.

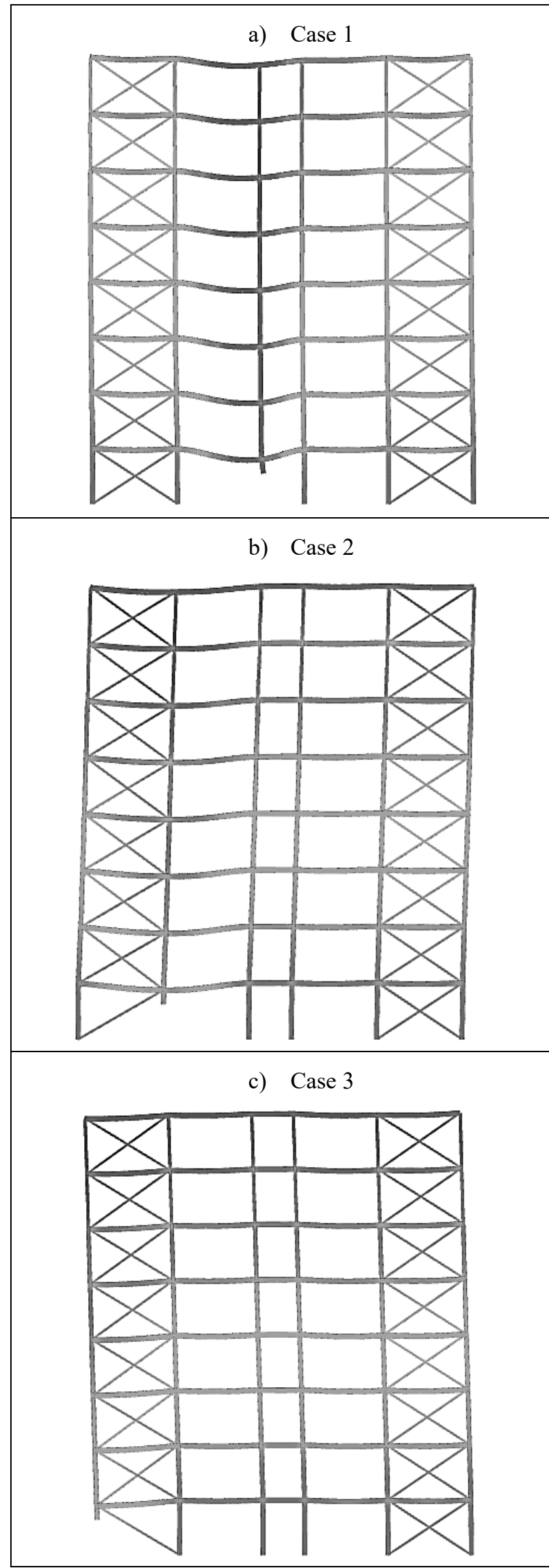

Fig. 7. Column removal scenarios.
The members in which the resistance is exceeded are shown in Fig. 8.

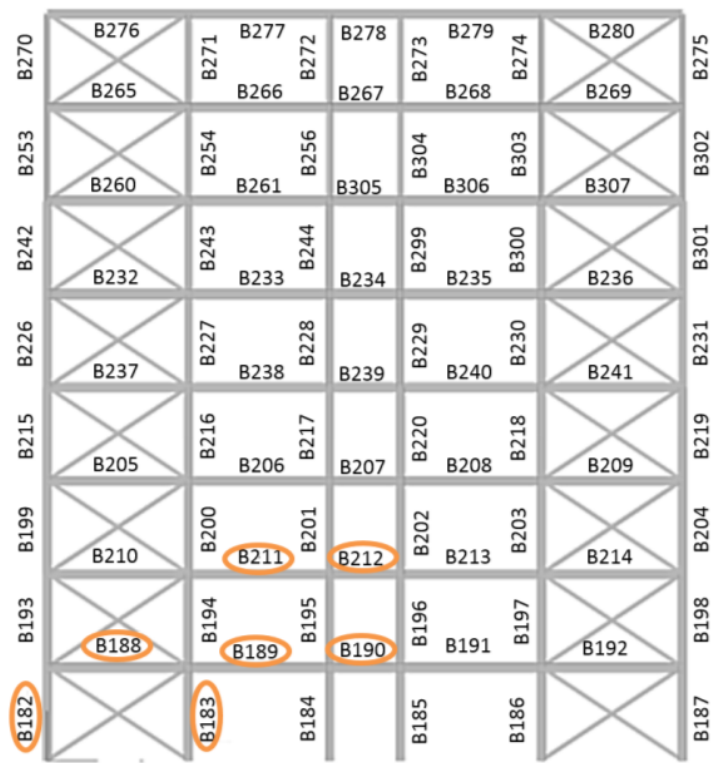

Fig. 8. The structural members over-utilised after the column removals.

\subsection{Assumptions to the static analysis of the accidental situation}

The list of sections that are used instead of the previous sections of the over-utilized members is given in Table 2. Taken into account the symmetry of the structure, this replacement relates also to the members that may be over-utilized if the location of the accidental event is on the right side. In general, the changes include all members of the first and second storey. The joints connecting the beams and columns with the exchanged sections are re-modelled and introduced into the frame model [9].

Table 2. List of the exchanged sections.

\begin{tabular}{|c|c|c|}
\hline $\begin{array}{c}\text { Type of } \\
\text { element }\end{array}$ & Bar numbers & Section \\
\hline $\begin{array}{c}\text { Primary } \\
\text { beam }\end{array}$ & $\begin{array}{c}\text { B188, B189, } \\
\text { B190, B191, B192 }\end{array}$ & $\begin{array}{c}\text { IPE 550 } \\
\text { (instead of } \\
\text { IPE 400) }\end{array}$ \\
\hline $\begin{array}{c}\text { Primary } \\
\text { beam }\end{array}$ & $\begin{array}{c}\text { B210, B211, B212, } \\
\text { B213, B214 }\end{array}$ & $\begin{array}{c}\text { IPE 450 } \\
\text { (instead of } \\
\text { IPE 400) }\end{array}$ \\
\hline Column & $\begin{array}{c}\text { B182, B183, B184, B185, } \\
\text { B186, B187, B193, B194, } \\
\text { B195, B196, B197, B198 }\end{array}$ & $\begin{array}{c}\text { HEB 400 } \\
\text { (instead of } \\
\text { HEB 360) }\end{array}$ \\
\hline
\end{tabular}

According to [2], for members (key elements) and any attached components, the ultimate strength should be taken into account instead of the yield strength. Therefore the selected members are calculated with the value of $f_{u}=360 \mathrm{~N} / \mathrm{mm}^{2}$ instead of $f_{y}=235 \mathrm{~N} / \mathrm{mm}^{2}$.

The localised area of admissible local failure should be taken as the smaller of $100 \mathrm{~m}^{2}$ and $15 \%$ from the total area of the building: $0.15 \times(27 \mathrm{~m} \mathrm{x} 36 \mathrm{~m})=145.8 \mathrm{~m}^{2}$. Therefore the localized area is taken as $100 \mathrm{~m}^{2}$. 
The surface load $A_{\mathrm{d}}$ should be transformed to the linear, uniformly distributed load of the value:

$$
A_{\mathrm{d}}{ }^{*}=34 \mathrm{kN} / \mathrm{m}^{2} \times 100 \mathrm{~m}^{2} / 27 \mathrm{~m}=125.92 \mathrm{kN} / \mathrm{m}
$$

In addition to the previous load schemes defined in the case of the normal designed situation, the new load case ACC1 is taken into consideration in which the lowest floor is loaded by $A_{d}$ *.

\subsection{Static analysis results of the frame in the design accidental situation}

The increase of the bending moments is observed due to the accidental situation. The maximum moment located at the span of the primary beam B188 (sagging moment) is equal to $481.27 \mathrm{kNm}$. The maximum hogging bending moment at the support is equal to $302.92 \mathrm{kNm}$. The dominant value is generated by the load combination defined as:

$$
\mathrm{G}+0.3 \mathrm{Q} 1+0.2 \mathrm{SL} 3+0.2 \mathrm{WL} 3+\mathrm{ACC} 1
$$

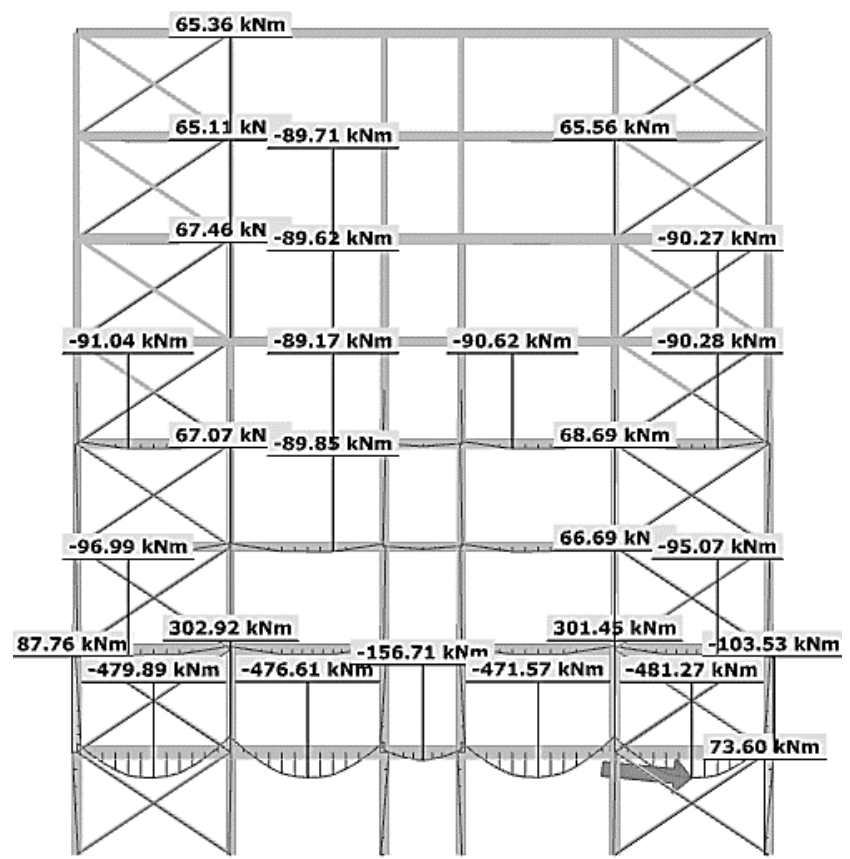

Fig. 9. Bending moment diagram with the max. $M_{E d}$ indicated.

The dominant normal force equal to $-2529.13 \mathrm{kN}$ is found in the column B183 within the load combination given by the formula (9):

$$
\mathrm{G}+0.3 \mathrm{Q} 4+0.2 \mathrm{SL} 2+0.2 \mathrm{WL} 1+\mathrm{ACC} 1
$$

The diagram of normal forces for the selected design load combination is shown in Fig. 10.

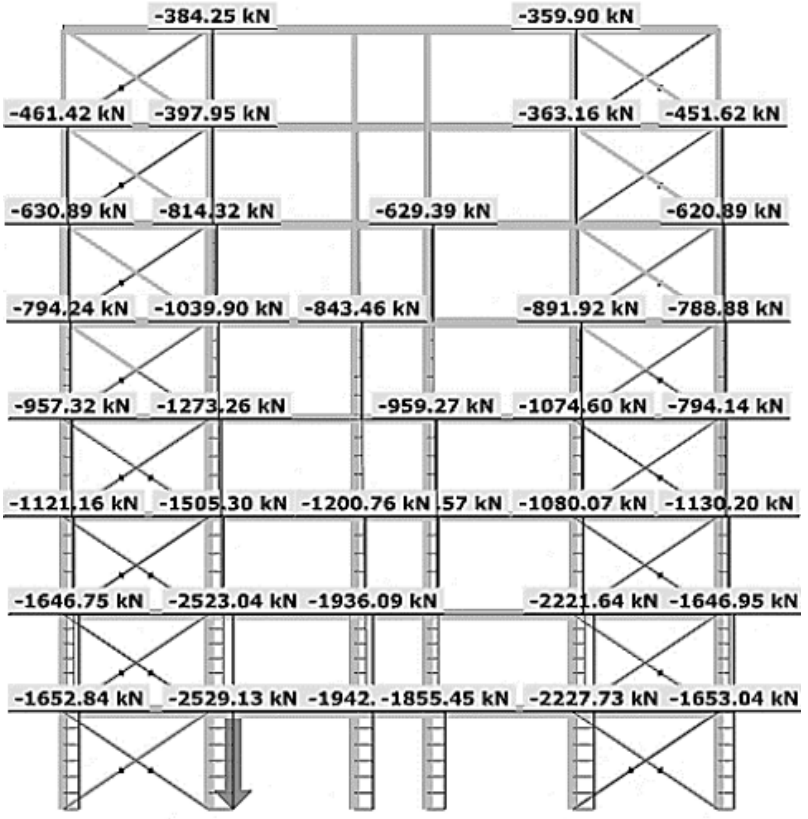

Fig. 10. Normal force diagram with the max. $N_{E d}$ indicated.

\subsection{Design of the frame subject to the accidental situation}

Global verification of the analysed frame, as well as the individual member checks according to [14], are conducted for the values of internal forces resulting from the analysis with the initial sway taken into account. The results of the utilisation of the selected members are given in Fig. 11.

Detailed design of joints in terms of the new static results is given in [9].

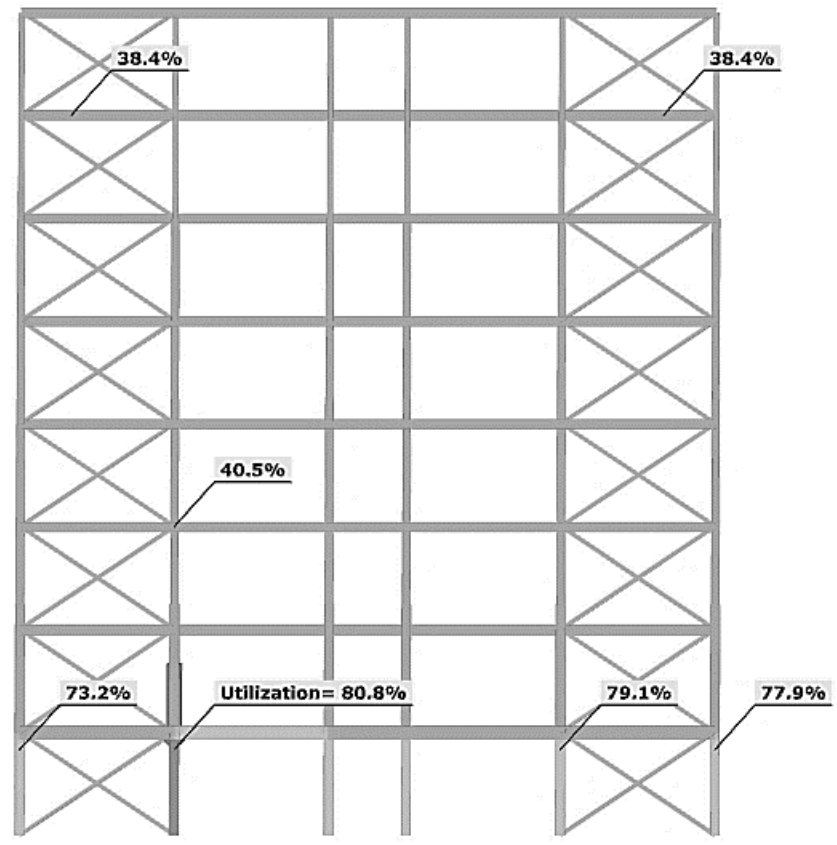

Fig. 11. The utilisation of the frame structural members. 


\section{Comparison of the results}

The comparison of the results between two cases (normal design situation and the accidental one) of the selected steel frame is summarised below.

Due to the accidental situation proposed for the upper risk building group, the increase of steel use is visible. Based on the steel tonnage calculated only for structural members (the mass of joints is excluded), the mass of the individual steel frame at the normal design situation equals $42.632 \mathrm{t}$. While for the accidental design situation, the mass of steel increases to $44.805 \mathrm{t}$, which means the steel use increase of about $5 \%$ for the given individual frame.

The other difference, in the two design approaches observed, is the great increase in bending moment in the primary beam due to the accidental load. The maximum sagging moment for the accidental situation increased almost three times in comparison to the normal design situation. However, the maximum value of the normal force in the internal column slightly decreases in the accidental situation, taking into account a decrease of the design values of the loads, other than the accidental, due to neglecting partial factors $\gamma_{G, j}$ and $\gamma_{Q, i}$ as well as the significant reduction of the combination factors $\psi$. And finally, the increase of the reference level of the steel properties by the adoption of the ultimate strength $f_{u}$ instead the yield strength $f_{y}$ in the accidental design situation.

\section{Conclusions}

Within the framework of this paper, the design of steel structure of the eight-storey building intended for a hotel is carried out, on the basis of Eurocodes. According to EN 1991-1-7 [2], the building is classified to the upper risk group - $\mathrm{CC} 2 \mathrm{~b}$ and therefore additional requirements to the design has to be applied. The steel structure of the hotel building should be checked in order to sustain an extent of localised failure from an unspecified cause without disproportionate collapse.

This purpose has been achieved by the studies including three parts. In the first part sections of the structural members as well as the semi-rigid beam-tocolumn joints are initially assumed and then checked for the normal loading situation. The second part is related to the study of the structure subjected to accidental damage due to a column loss. Three various accidental load cases are considered, in which the columns of the lowest storey are removed from three different positions.

Finally a design of the framed structure subjected to the accidental situation according to EN 1991-1-7 [2] has been performed using the key elements method. This method is based on selection of the structural elements that are notified as the most critical and adoption of the recommended value of the accidental load $A_{d}$ equal to $34 \mathrm{kN} / \mathrm{m}^{2}$, simulating an exceptional event within the accidental load combinations. It is applied to the floor of the first storey as the linear load, taken from the area limited to $100 \mathrm{~m}^{2}$. The bigger sections of the columns and the primary beams of the first and the second storey has to be adopted as well as for the purpose of the resistance verification of the selected structural members, the yield strength is replaced by the value of the ultimate strength. This increase of the cross-sections provided the necessity of modelling new semi-rigid joints, which were also applied to the global static analysis. The design calculations of the most utilized members representing each section group are performed, taking into account the effects of flexural buckling, lateral-torsional buckling and their interactions. Adopted strategy provide the building structure with sufficient robustness to survive a reasonable range of undefined accidental actions with the relatively small increase in steel consumption.

\section{References}

1. EN 1990:2002+A1, Eurocode - Basis of structural design (CEN, 2005)

2. EN 1991-1-7, Eurocode 1 - Actions on structures Part 1-7: General actions - Accidental actions (CEN, 2006)

3. A. G. J. Way, Structural robustness of steel framed buildings, (SCI P391, Ascot, 2011)

4. Ch M. Foley, K. Martin, C. Schneeman, Robustness in structural steel framing systems, Final report (AISC, Chicago, 2007)

5. U. Kuhlmann, L. Rölle, J.-P. Jaspart et al., Robust structures by joint ductility, Final Report (RFCS, European Communities, Luxembourg, 2009)

6. H. M. Elsanadedy, T. H Almusallam, Y. R. Alharbi, Y.A. Al-Salloum, H. Abbas, J. Constr. Steel Res. 101, 143-157 (2014)

7. B. Jiang, G.-Q. Li, A. Usmani, J. Constr. Steel Res. 115, 160-168 (2015)

8. C. G. Tay, C. G, Koh, J. Y. R Liew, J. Constr. Steel Res. 122, 395-408 (2016)

9. F. Al-Sahar, Design of steel structure of a multistorey building subjected to accidental damage due to a column loss, Master Thesis (Warsaw University of Technology, 2017)

10. EN 1991-1-3, Eurocode 1 - Actions on structures Part 1-3: General actions - Snow loads (CEN, 2003)

11. EN 1991-1-4:2005+A1, Eurocode 1 - Actions on structures - Part 1-4: General actions - Wind actions (CEN, 2010)

12. PN-EN 1991-1-4, Eurokod 1 - Oddziaływania na konstrukcje - Część 1-4: Oddziaływania ogólne Oddziaływania wiatru (PKN, 2008)

13. EN 1991-1-1, Eurocode 1 - Actions on structures Part 1-1: General actions - Densities, self-weight, imposed loads for buildings (CEN, 2002)

14. EN 1993-1-1, Eurocode 3 - Design of steel structures - Part 1-1: General rules and rules for buildings (CEN, 2005)

15. EN 1993-1-8, Eurocode 3 - Design of steel structures - Part 1-8: Design of joints (CEN, 2005) 